\title{
Infant T-Cell Acute Lymphoblastic Leukemia Presenting with Macrocephaly: A Case Report
}

Victoria Brocksmith ${ }^{1}$, Sudarshawn Damodharan ${ }^{1}$, Mallery Olsen $^{2}$, Susan Rebsamen ${ }^{2}$, and Margo Hoover-Regan ${ }^{2}$

${ }^{1}$ University of Wisconsin Madison

${ }^{2}$ University of Wisconsin Madison School of Medicine and Public Health

May 14, 2020

\begin{abstract}
A 6.5-month-old girl presented to a pediatrician for a second opinion regarding worsening macrocephaly and developmental regression. She then underwent neurosurgical evaluation. Rapid-sequence magnetic resonance imaging was significant for benign enlargement of the subarachnoid space of infancy. A complete blood count was significant for $33 \%$ blasts in the peripheral blood. Flow cytometry of the peripheral blood established a diagnosis of T-cell Acute Lymphoblastic Leukemia (ALL). T-cell ALL has been rarely reported and our patient's presentation with macrocephaly is particularly unique.
\end{abstract}

\section{Hosted file}

Tcell CR 5_13-converted.pdf available at https://authorea.com/users/321761/articles/450952infant-t-cell-acute-lymphoblastic-leukemia-presenting-with-macrocephaly-a-case-report

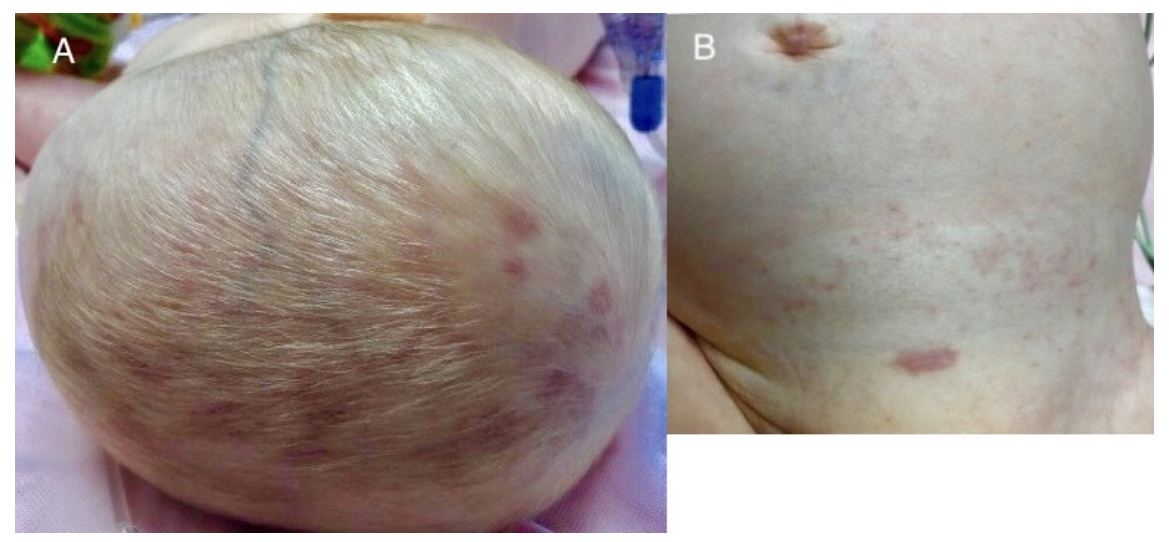

